\title{
Histological changes in the thyroid in cirrhosis of the liver
}

\author{
A. NICOL AND G. SCLARE \\ From the Department of Pathology, University of Manchester
}

SYNOPSIS The thyroid has been examined histologically in 77 cases of cirrhosis of the liver and in an equal number of control cases. Contrary to expectation, no difference was found between the incidence or the severity of lymphocytic infiltration of the thyroid in the two groups. A conspicuous fibrosis or 'cirrhosis' of the thyroid, not related to lymphocytic infiltration, was associated with cirrhosis of the liver, especially in elderly women. The significance of this lesion is not clear but its origin is probably to be sought in liver dysfunction rather than in auto-immunization.

Since Paul (1865) noted the presence of cirrhosis of the liver in a case of thyrotoxicosis, reports linking the two conditions have been plentiful. Good summaries have been given by McIver (1942), Lichtman (1953), and Popper and Schaffner (1957). More recently, with the dawn of the immunological era in thyroid pathology, attention has turned to a possible association between chronic thyroiditis and cirrhosis of the liver. The initial observations on abnormal 'liver function tests' in Hashimoto's disease (Cooke and Wilder, 1954; Skirpan, Reich, and Crile, 1955; Skillern, Crile, McCullagh, Hazard, Lewis, and Brown, 1956) were followed by reports of coexisting thyroiditis and liver disease (Luxton and Cooke, 1956; Roitt and Doniach, 1958; McConkey and Callaghan, 1960), and by evidence linking hepatic cirrhosis with the presence of circulating thyroid autoantibodies (Goudie, Anderson, and Gray, 1959).

All the earlier observations relating diseases of the two organs were based on the assumption that the abnormality in the thyroid preceded that in the liver. The more recent work raises the possibility that the two abnormalities might be the result of a single, possibly auto-immune, disorder, affecting both organs more or less simultaneously. We considered that a new approach might be made by assessing the condition of the thyroid in cases of established liver disease.

\section{MATERIAL AND METHODS}

Necropsies performed at Manchester Royal Infirmary over a six-year period (July 1954 to June 1960) were

Received for publication 15 May 1961. reviewed. Of a total of 2,910 consecutive necropsies, 116 were cases of hepatic cirrhosis (portal, biliary, or cardiac), an incidence of $4 \%$. Excluding all cases in which sections of thyroid were not available, and cases in which the degree of cirrhosis could not be assessed because of the presence of primary or secondary neoplasm in the liver, 77 cases of cirrhosis remained for study. These consisted of 43 males (age range 19 to 85 years, mean 50.8) and 34 females (age range 27 to 74 years, mean 57.4). Fiftyfour cases were classified as portal, 14 as biliary, and nine as cardiac cirrhosis.

Sections were stained with haematoxylin and eosin; when required, reticulin (modified Foot) and connective tissue (picro-Mallory) stains on the liver sections were also employed.

An equal number of control cases was studied, matched for age and sex with the cirrhotic cases; the control cases had a normal histological pattern in the liver, and no clinical evidence of thyroid or other endocrine abnormality. Taking all cases in chronological sequence, one of us examined the sections of liver, without reference to the state of the thyroid; the other reviewed the sections of thyroid, working independently and without knowledge of the clinical or pathological findings.

\section{RESULTS}

In the initial review of the thyroid sections, attention was focused on the presence of lymphocytic infiltration. As would be expected from the average age of the subjects, minor degrees of lymphocytic infiltration were very common. The occurrence of up to three tiny perivascular lymphocytic aggregations, without other histological abnormality, was noted in 20 cases of cirrhosis and in 13 controls. It was considered, however, to be largely a matter of chance whether such trivial lesions appeared in a random 
section of any gland, and lymphocytic infiltration of this order was eliminated from the final assessment of results. Greater degrees of lymphocytic infiltration were recorded in three arbitrary grades, the highest grade being reserved for examples in which lymphocytic infiltration replaced one quarter or more of the gland substance.

The incidence of lymphocytic infiltration in each group is recorded in Table I. In both groups,

\section{TABLE I}

INCIDENCE OF LYMPHOCYTIC INFILTRATION IN THE THYROID

\begin{tabular}{|c|c|}
\hline $\begin{array}{l}\text { No. of Cases } \\
\text { Examined in } \\
\text { Each Group }\end{array}$ & $\begin{array}{l}\text { No. of Cases showing } \\
\text { Lymphocytic } \\
\text { Infiltration }^{1}\end{array}$ \\
\hline & Cirrhotic \\
\hline
\end{tabular}

\begin{tabular}{llrrr}
\hline Under 50 years & Male & 20 & 1 & 1 \\
& Female & 8 & 2 & 2 \\
50 years and over & Male & 23 & 3 & 6 \\
& Female & 26 & 11 & 11 \\
Total (all ages, both sexes) & 77 & 17 & 20
\end{tabular}

'The difference between the cirrhotic and control groups is not statistically significant.

lymphocytic infiltration was commoner in females, especially those over 50 years of age. The incidence of the lesion in the cirrhotic group was not significantly different from that in the control group. There was, moreover, no difference in the severity of the lesion in the two groups (Table II) and no tendency for the more severe degrees to be associated with the more severe degrees of liver damage (Table III).

TABLE II

DEGREE OF LYMPHOCYTIC INFILTRATION IN THE THYROID

\begin{tabular}{cccccc}
$\begin{array}{l}\text { Degree of Lymphocytic } \\
\text { Infiltration in Thyroid }\end{array}$ & \multicolumn{2}{l}{ No. of Cases in Each Group } \\
\cline { 2 - 5 } & \multicolumn{2}{l}{ Cirrhotic } & & \multicolumn{2}{l}{ Control } \\
\cline { 2 - 5 } \cline { 5 - 6 } & $M$ & $F$ & & $M$ & $F$ \\
\hline Nil & 39 & 21 & & 36 & 21 \\
+ & 3 & 7 & & 6 & 6 \\
++ & 1 & 4 & & 1 & 5 \\
+++ & 0 & 2 & & 0 & 2
\end{tabular}

TABLE III

RELATION OF DEGREE OF LYMPHOCYTIC INFILTRATION IN THYROID TO DEGREE OF CIRRHOSIS IN LIVER

\begin{tabular}{|c|c|c|c|c|c|c|c|c|}
\hline \multirow{3}{*}{$\begin{array}{l}\text { Degree of } \\
\text { Lymphocytic } \\
\text { Infiltration in } \\
\text { Thyroid }\end{array}$} & \multicolumn{8}{|c|}{ Degree of Cirrhosis in Liver } \\
\hline & \multicolumn{2}{|l|}{+} & \multicolumn{2}{|c|}{++} & \multicolumn{2}{|c|}{+++} & \multicolumn{2}{|c|}{++++} \\
\hline & $M$ & $\boldsymbol{F}$ & $\boldsymbol{M}$ & $\boldsymbol{F}$ & $\boldsymbol{M}$ & $\boldsymbol{F}$ & $M$ & $\boldsymbol{F}$ \\
\hline $\begin{array}{l}\text { Nil } \\
+ \\
++ \\
+++\end{array}$ & $\begin{array}{l}6 \\
2 \\
0 \\
0\end{array}$ & $\begin{array}{l}6 \\
1 \\
0 \\
0\end{array}$ & $\begin{array}{l}8 \\
1 \\
0 \\
0\end{array}$ & $\begin{array}{l}5 \\
4 \\
2 \\
1\end{array}$ & $\begin{array}{r}11 \\
0 \\
1 \\
0\end{array}$ & $\begin{array}{l}2 \\
1 \\
1 \\
1\end{array}$ & $\begin{array}{r}14 \\
0 \\
0 \\
0\end{array}$ & $\begin{array}{l}8 \\
1 \\
1 \\
0\end{array}$ \\
\hline
\end{tabular}

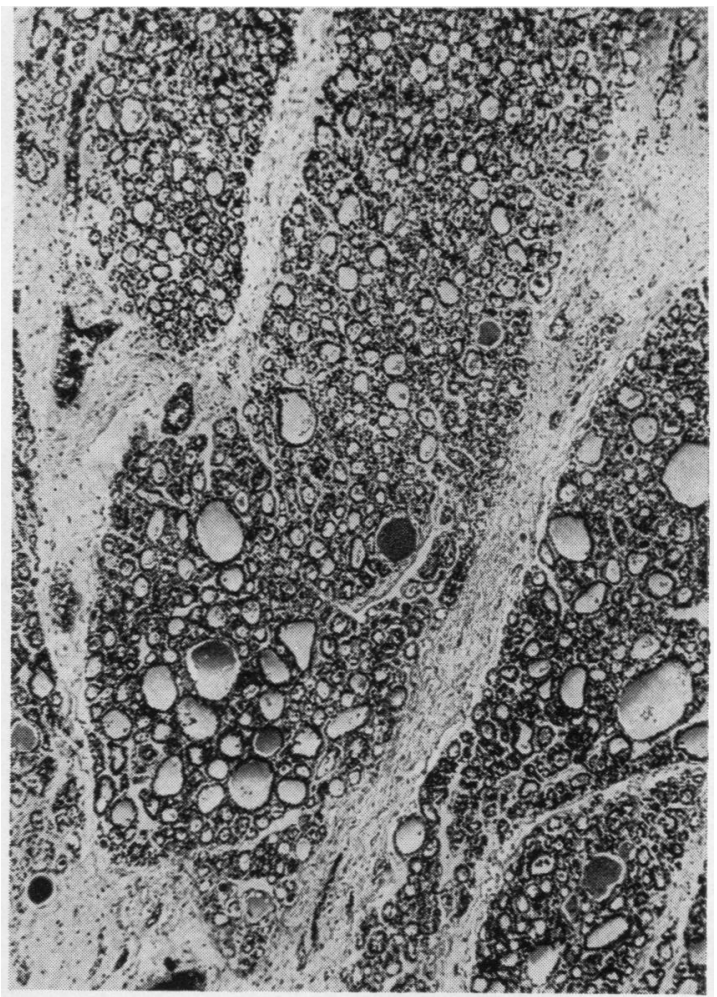

FIG. 1. Fibrosis of the thyroid, without lymphocytic infiltration or any abnormality of the acinar pattern. Haematoxylin and eosin, $\times 55$.

During the examination of the thyroid sections, it was noted that some showed an unusual degree of fibrosis, with little or no lymphocytic infiltration and no disturbance of the normal acinar structure and arrangement (Fig. 1). As this is a picture not commonly seen in the thyroid, the sections were reviewed again, still without knowledge of the clinical or pathological findings, and all examples of this type of fibrosis were noted. Simple thickening of the interlobular septa was not recorded, as this merged imperceptibly with the normal picture. Fibrosis was recorded only when it encroached on the parenchyma, enclosing groups of acini or even single acini.

Fibrosis is, of course, a common accompaniment of focal or diffuse thyroiditis, but examples obviously associated with thyroiditis were excluded, and fibrosis was recorded only in the absence of lymphocytic infiltration or when it was clearly out of proportion to the trivial degree of lymphocytic infiltration. These cases lacked the epithelial changes which ordinarily accompany focal or diffuse thyroiditis, namely, 
oxyphilic epithelium ('Hürthle cells'), small acini lined by columnar epithelium and containing syncytial macrophages, and compact groups of epithelial cells with little or no lumen. Fibrosis occurring either in the capsule or in the substance of a thyroid nodule, of whatever type, was also excluded.

The incidence of fibrosis in each group is recorded in Table IV. Twenty-three examples occurred in the

\section{TABLE IV}

INCIDENCE OF FIBROSIS IN THE THYROID

\begin{tabular}{llcccc} 
& & $\begin{array}{l}\text { No. of Cases } \\
\text { Examined in } \\
\text { Each Group }\end{array}$ & $\begin{array}{l}\text { No. of Cases Showing } \\
\text { Fibrosis }\end{array}$ & \\
\cline { 4 - 5 } & & & Cirrhotic & Control \\
\hline Under 50 years & Male & 20 & 3 & 3 \\
& Female & 8 & 1 & 0 \\
50 years and over & Male & 23 & 8 & 3 \\
& Female & 26 & 11 & 2 \\
Total (all ages and both sexes) & 77 & 23 & 8
\end{tabular}

Considering the figures for males of all ages, the difference between the cirrhotic and control groups is not statistically significant.

Considering the figures for females of all ages, there is a highly significant association of the lesion with cirrhosis $(P=<0.01)$.

Combining the figures for both sexes of ages 50 and over, the difference in the two groups is statistically highly significant $(P=<0.01)$.

cirrhotic group and eight in the control group. When females alone were considered, the increased incidence in the cirrhotic group was highly significant, and so also was the increased incidence in all cases of cirrhosis (combining the figures for both sexes) aged 50 years and over.

Fibrosis was recorded in three arbitrary grades; the results, shown in Table $\mathrm{V}$, indicate more clearly

\section{TABLE V}

DEGREE OF FIBROSIS IN THE THYROID

\begin{tabular}{|c|c|c|c|c|}
\hline \multirow{3}{*}{$\begin{array}{l}\text { Degree of Fibrosis in } \\
\text { the Thyroid }\end{array}$} & \multicolumn{4}{|c|}{ No. of Cases in Each Group } \\
\hline & \multicolumn{2}{|c|}{ Cirrhotic } & \multicolumn{2}{|c|}{ Control } \\
\hline & $M$ & $F$ & $M$ & $\boldsymbol{F}$ \\
\hline Nil & 32 & 22 & 37 & 32 \\
\hline+ & 7 & 4 & 6 & 2 \\
\hline+1 & 3 & 2 & 0 & 0 \\
\hline+1 & 1 & 6 & 0 & 0 \\
\hline
\end{tabular}

the relationship between thyroid fibrosis and hepatic cirrhosis. Twelve cases of cirrhosis, but none of the controls, wcre assigned to the two higher grades. The numbers in each category are too small to indicate clearly whether or not there is a direct relationship between the degree of thyroid fibrosis and the degree of liver damage but the results are suggestive of such a relationship (Table VI).

With regard to the incidence of lymphocytic infiltration and of fibrosis in the thyroid in the different types of hepatic cirrhosis, the biliary and
TABLE VI

RELATION OF DEGREE OF FIBROSIS IN THE THYROID TO DEGREE OF CIRRHOSIS IN THE LIVER

\begin{tabular}{|c|c|c|c|c|c|c|c|c|}
\hline \multirow{3}{*}{$\begin{array}{l}\text { Degree of } \\
\text { Fibrosis in } \\
\text { Thyroid }\end{array}$} & \multicolumn{8}{|c|}{ Degree of Cirrhosis in Liver } \\
\hline & \multicolumn{2}{|l|}{+} & \multicolumn{2}{|c|}{++} & \multicolumn{2}{|c|}{$+t+$} & \multicolumn{2}{|c|}{$+t+t$} \\
\hline & $M$ & $F$ & $M$ & $F$ & $M$ & $\boldsymbol{F}$ & $M$ & $\boldsymbol{F}$ \\
\hline Nil & 7 & 3 & 7 & 9 & 9 & 3 & 9 & 7 \\
\hline+ & 1 & 3 & 1 & $\mathbf{0}$ & 4 & $\mathbf{0}$ & 1 & 1 \\
\hline++ & $\mathbf{0}$ & 1 & $\mathbf{0}$ & 1 & 1 & $\mathbf{0}$ & 2 & $\mathbf{0}$ \\
\hline$+t+$ & $\mathbf{0}$ & $\mathbf{0}$ & 0 & 2 & $\mathbf{0}$ & 2 & 1 & 2 \\
\hline
\end{tabular}

cardiac groups are smaller than one would require for separate assessment, but judging by the material available, the incidence and severity of both these lesions in the thyroid were not dependent on the type of hepatic cirrhosis.

\section{DISCUSSION}

There can be little doubt that hyperthyroidism, if of sufficient duration and severity, may lead to various forms of liver damage, ranging from the most trivial lesions to established cirrhosis. It has been suggested that hyperthyroidism leads to a distinctive type of cirrhosis (Habán, 1933; Rössle, 1933; Weller, 1933; Moschcowitz, 1946), but Popper and Schaffner (1957) do not consider this 'fairly specific' type of cirrhosis to be the one most frequently found in hyperthyroidism. None of our cases, it may be noted here, could be classified as 'cirrhosis basedowiana'.

In the many studies of liver changes in hyperthyroidism, little attention was paid to the histological appearance of the thyroid, but where this was mentioned comment was made on the presence of lymphocytic infiltration (Shaffer, 1940; Wallerstein and Walker, 1949), foreshadowing the later observations relating thyroiditis to cirrhosis.

Suspicion that liver disease might also accompany chronic thyroiditis arose with the report by Cooke and Wilder (1954) of abnormal colloidal gold tests in two cases of Hashimoto's disease. Other tests depending on disturbances of the serum proteins were similarly found to give abnormal results in chronic thyroiditis (Skirpan et al., 1955; Skillern et al., 1956; Luxton and Cooke, 1956) and also in subacute thyroiditis (Stemmermann, 1956). The discovery of circulating autoantibodies in Hashimoto's disease (Roitt, Doniach, Campbell, and Hudson, 1956) raised the possibility that the serum protein abnormalities might reflect not a disturbance of liver function but merely the presence of thyroid autoantibody. Indeed, Allison (1949), reporting abnormal liver function tests in thyrotoxicosis, noted that the sensitivity pattern of the different tests did 
not accord with the reported sensitivities in miscellaneous hepatic disorders, and suggested prophetically that some mechanism other than actual hepatic damage might be responsible for the results obtained.

The question is not easily resolved, as an increase in gamma globulin which can be due to a high level of thyroglobulin autoantibody (Roitt, Campbell, and Doniach, 1958), is likewise a characteristic feature of portal cirrhosis (Sherlock, 1958).

One of the patients described by Luxton and Cooke (1956), however, was proved to have advanced cirrhosis, and Roitt and Doniach (1958) mentioned liver disease in four cases of thyroiditis. McConkey and Callaghan (1960) reported two examples of death from liver failure in chronic thyroiditis, and a further case in which the thyroid at necropsy 'suggested typical myxoedema'.

The subject was approached from a different angle by Goudie et al. (1959), who carried out complement-fixation tests for thyroid autoantibody in patients without clinical evidence of thyroid disease. Nine of the patients whose sera had given positive tests came to necropsy. In three, the diagnosis was cirrhosis of the liver (multilobular in two, monolobular in one); in another, the subsidiary diagnoses included fatty liver, and in another monolobular cirrhosis; all five were elderly women. The same authors reported that in nine of 11 women with hepatic necrosis or cirrhosis, the thyroid showed focal thyroiditis. Perhaps their most significant observation was a high incidence of positive complement-fixation tests, in women only, in cases of hepatic necrosis or cirrhosis; in no other disease was a statistically significant incidence of positive tests found. A study of 33 cases of cirrhosis in this laboratory (Taylor and Nicol, 1960), employing the tanned cell agglutination test, also revealed an unduly high incidence of positive tests in elderly women with cirrhosis of the liver (Table VII). On the other

\section{TABLE VII}

INCIDENCE OF THYROID AUTO-ANTIBODIES IN CIRRHOTIC AND NON-CIRRHOTIC SUBJECTS

(TANNED CELL AGGLUTINATION TEST)

\begin{tabular}{llcc}
\hline \multirow{4}{*}{ Males } & $\begin{array}{c}\text { No. of Cases } \\
\text { Examined }\end{array}$ & $\begin{array}{c}\text { No. of Cases with } \\
\text { Antibody }\end{array}$ \\
\multirow{4}{*}{ Females } & Cirrhotics & 11 & 2 \\
& Controls & 108 & 4 \\
& Cirrhotics & 22 & 8 \\
& Controls & 92 & 11
\end{tabular}

hand, a report by Hackett and his colleagues in Australia on several hundred patients with nonthyroid conditions showed that positive tests occurred in a wide variety of diseases; cirrhosis and acute hepatocellular disease were not among those giving the highest number of positive results, either by the complement-fixation test, substituting normal for thyrotoxic thyroid extract as the antigen (Hackett, Beech, and Forbes, 1960a), or by the tanned cell agglutination test (Hackett et al., 1960b).

The occasional instances of cross-reactions between Hashimoto sera and extracts of liver are probably not significant in this connexion, as similar cross-reactions occur with extracts of other organs (Roitt and Doniach, 1958; Anderson, Goudie, and Gray, 1959); these reactions are probably due to non-specific antibodies of the type described by Gajdusek (1958).

It is noteworthy that in thyroiditis, as in hyperthyroidism, the accumulating evidence of associated hepatic disease has referred to a variety of liver lesions, and has not singled out any individual type of cirrhosis as being commonly associated with the thyroid abnormality. It is for this reason that we felt justified in including al! types of cirrhosis in our study, the more so as it is often a matter of great difficulty to distinguish the different types in the advanced stage so often seen at necropsy.

An attractively simple explanation for some of the above results would be that thyroiditis and cirrhosis are simultaneous manifestations of a single auto-immune disorder, as suggested by McConkey and Callaghan (1960). The possibility cannot be denied but our results do nothing to encourage such a view. Taking lymphocytic infiltration as a measure of auto-immunization, one would have expected a substantially increased incidence of lymphocytic infiltration of the thyroid in cases of hepatic cirrhosis. We have been unable to demonstrate any difference in this respect between the cirrhotic and control groups.

The fibrosis of the thyroid which we have found to be significantly associated with cirrhosis of the liver is an obscure lesion, strikingly different from the fibrosis of chronic thyroiditis or myxoedema. We feel that 'cirrhosis of the thyroid' is a suitable term for this lesion, since the pattern of fibrosis is similar to that seen in cirrhosis of the liver. We use the term in a purely descriptive sense, without any implications as to the pathogenesis of the lesion. The fundamental differences in structure and function between liver and thyroid are sufficient to deter us from drawing too close an analogy between the lesions in the two organs.

On morphological grounds, the thyroid lesion cannot readily be accepted as a late or healed stage of focal thyroiditis. Disappearance of the inflammatory infiltrate, or diminution to such a degree, would scarcely be expected, since even in the advanced diffuse fibrosis of myxoedema it is usual to find a conspicuous lymphocytic infiltration. The absence of oxyphilic epithelium, and of the other epithelial changes which occur in both focal and 
diffuse thyroiditis, further distinguishes the two conditions, and in any event the lattice-work of fibrosis is quite unlike the spotty distribution of focal thyroiditis. On the other hand, one cannot but be struck by the close correspondence in age and sex incidence to the focal thyroiditis of clinically normal thyroids, and it would not be justifiable to dismiss altogether the possibility that 'thyroid cirrhosis' is a late stage of lymphocytic infiltration and the process of auto-immunization.

Other explanations must be considered. The 'cirrhosis of the thyroid' could be the end stage of diffuse epithelial hyperplasia which might have occurred with or without clinical evidence of hyperthyroidism.

Degenerative arterial disease, causing ischaemia, might be implicated by the age incidence, but we have not found it to be a factor of importance. In any event, the preponderance of females favours more the sex incidence of thyroid disease generally than that of arterial disease.

We consider it more likely that the lesion in the thyroid is initiated by the primary damage in the liver. It is known that hepatic insufficiency may result in a failure to inactivate and excrete endogenous oestrogens (Bennett, Baggenstoss, and Butt, 1950). Excess oestrogens have produced fibrosis in the genital tract of the rat (Burack, Wolfe, and Wright, 1942) and fibroblastic proliferation in the human testis (de la Balze, Mancini, Bur, and Irazu, 1954). It has been suggested that fibrosis in the human female breast is not a direct consequence of epithelial hyperplasia but is mediated through hyperoestrogenism (Vassar and Culling, 1959). The liver is also concerned in the metabolism and excretion of thyroid hormone (Pitt-Rivers and Tata, 1959); hepatic insufficiency might lead to retention of this hormone with consequent fibrous atrophy in the parent organ. Other disturbances of connective tissue have been noted in hepatic cirrhosis; a high incidence of pancreatic fibrosis has been recorded by Kirshbaum and Shure (1943) and by Stinson, Baggenstoss, and Morlock (1952), an observation confirmed by examination of the sections of the pancreas in the present series; further, the incidence of Dupuytren's contracture has been noted to be greater in cases of hepatic cirrhosis than in a control series (Wolfe, Summerskill, and Davidson, 1956).
There is at present no positive evidence in favour of any of these possibilities, but the occurrence of 'cirrhosis of the thyroid' in association with several $\stackrel{\vec{F}}{\stackrel{7}{2}}$ types of liver damage, of varying aetiology, points to disordered liver function as the principal factor in pathogenesis.

We wish to thank Professor A. C. P. Campbell for helpful $\stackrel{\mathbb{\nabla}}{\circ}$ advice and criticism, Dr. J. E. Leeson for the statistical in analysis and Mr. N. Mowat for the photomicrograph.

\section{REFERENCES}

Allison, A., Jr. (1949). Glasg. med. J., 30, 417.

Anderson, J. R., Goudie, R. B., and Gray, K. G. (1959). Scot. med. $J ., 4,64$.

Balze, F. A. de la, Mancini, R. E., Bur, G. E., and Irazu, J. (1954). Fertil. and Steril., 5, 421.

Bennett, H. S., Baggenstoss, A. H., and Butt, H. R. (1950). Amer. J. clin. Path., $20,814$.

Burack, E., Wolfe, J. M., and Wright, A. W. (1942). Endocrinology, $30,335$.

Cooke, R. T., and Wilder, E. (1954). Lancet, 1, 984.

Gajdusek, D. C. (1958). A.M.A. Arch. intern. Med.. $101,9$.

Goudie, R. B., Anderson, J. R., and Gray, K. G. (1959). J. Path. Bact., 77, 389.

Habán, G. (1933). Beitr. path. Anat., 92, 88.

Hackett, E., Beech, M., and Forbes, I. J. (1960a). Aust. Ann. Med., 9, 叉 93. (1960b). Lancet, 2, 402.

Kirshbaum, J. D., and Shure, N. (1943). J. Lab. clin. Med., 28, 721. Lichtman, S. S. (1953). Diseases of the Liver, Gallbladder and Bile Ducts, 3rd ed., Vol. 2, p. 924. Lea and Febiger, Philadelphia. Luxton, R. W., and Cooke, R. T. (1956). Lancet, 2, 105.

McConkey, B., and Callaghan, P. (1960). Ibid., 1, 939.

McIver, M. A. (1942). Surgery, 12, 654.

Moschcowitz, E. (1946). Arch. intern. Med., 78, 497.

Paul (1865). Berl. klin. Wschr., 2, 277.

Pitt-Rivers, R., and Tata, J. R. (1959). The Thyroid Hormones, Ch. 8. Pergamon Press, London.

Popper, H., and Schaffner, F. (1957). Liver: Structure and Function, p. 484. McGraw-Hill, New York.

Roitt, I. M., Campbell, P. N., and Doniach, D. (1958). Biochem. J. $69,248$.

- and Doniach, D. (1958). Lancet, 2, 1027.

,-- Campbell, P. N., and Hudson, R. V. (1956). Ibid., 2, 820

Rössle, R. (1933). Virchows Arch. path. Anat., $291,1$.

Shaffer, J. M. (1940). Arch. Path. (Chicago), 29, 20.

Sherlock, S. (1958). Diseases of the Liver and Biliary System, 2nd ed., p. 37. Blackwell, Oxford.

Skillern, P. G., Crile, G., Jr., McCullagh, E. P., Hazard, J. B., Lewis, L. A., and Brown, H. (1956). J. clin. Endocr., 16, 35.

Skirpan, P., Reich, A., and Crile, G., Jr. (1955). Amer. J. clin. Path., $25,1274$.

Stemmermann, G. N. (1956). J. Amer. med. Ass., 162, 31

Stinson, J. C., Baggenstoss, A. H., and Morlock, C. G. (1952). Amer. J. clin. Path., 22, 117.

Taylor, G., and Nicol, A. (1960). Unpublished observations.

Vassar, P. S., and Culling, C. F. A. (1959). A.M.A. Arch. Path., 67, N 128 .

Wallerstein, R. S., and Walker, W. J. (1949). Ann. intern. Med., 31, 904.

Weller, C. V. (1933). Ibid., 7, 543.

Wolfe, S. J., Summerskill, W. H. J., and Davidson, C. S. (1956). New Engl. J. Med., 255, 559. 